\title{
Peroral endoscopic dual myotomy (dual POEM) for achalasia with severe esophageal dilatation
}

Although the high effectiveness of endoscopic or surgical myotomy for treating achalasia has been well recognized, persistent or recurrent symptoms may develop following the procedure [1,2]. A review has summarized the negative predictors of myotomy for achalasia patients, which include severe preoperative dysphagia and the presence of an enlarged esophagus [3]. Subsequent reports revealed that repeated myotomy on the same side or the opposite side can be performed with positive outcomes in such patients $[1,4,5]$. Herein, we describe a peroral endoscopic dual myotomy (dual POEM) technique, in which dual myotomies are performed during a single procedure, to avoid repeat intervention for achalasia patients with negative predictors.

A 42-year-old man presented with chronically worsening dysphagia, and was diagnosed with achalasia ( $\triangleright$ Fig. 1 a). Following informed consent, a dual POEM procedure was performed ( $\downarrow$ Video 1 ), with the patient under general anesthesia. First, submucosal injection of saline mixed with methylene blue was performed into the posterior esophageal wall. Mucosal entry at $7 \mathrm{~cm}$ above the gastroesophageal junction was initially made using a hybrid knife ( $\mathbf{F i g} \mathbf{2}$ a). A wide submucosal tunnel, occupying at least half of the esophageal lumen, was then created ( $\boldsymbol{\nabla}$ Fig. $\mathbf{2}$ b). Dual myotomies were performed successively at the 8 o'clock and 3 o'clock positions, respectively, and muscle was cut to a point $2 \mathrm{~cm}$ below the cardia ( $\nabla$ Fig. $2 \mathbf{c}$ ). The mucosal entry was finally closed using clips ( $\mathbf{F i g . 2 d}$ ). The procedure was successfully performed without any adverse events.

A nasogastric tube was placed for 2 days. The patient resumed a liquid diet on Day 3 after the procedure, and a normal diet was allowed at 2 weeks. At 1 -month follow-up, the patient reported significant

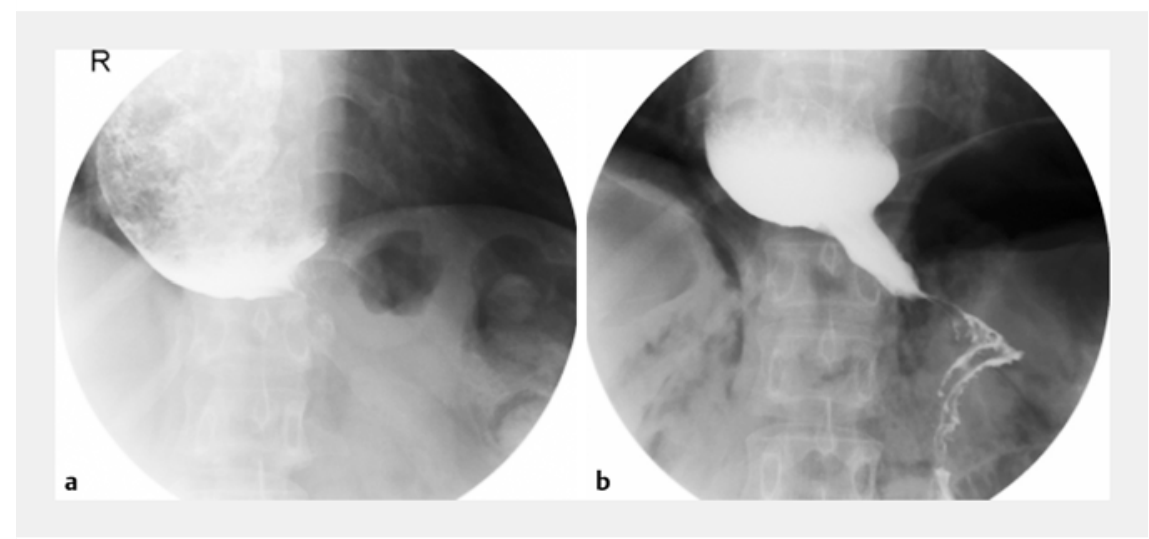

- Fig. 1 Timed barium swallow esophagography. a Preoperative esophagography noted severe esophageal dilatation and no obvious passage of barium. b Postoperative esophagography demonstrated a rapid passage of barium from esophagus into the stomach.

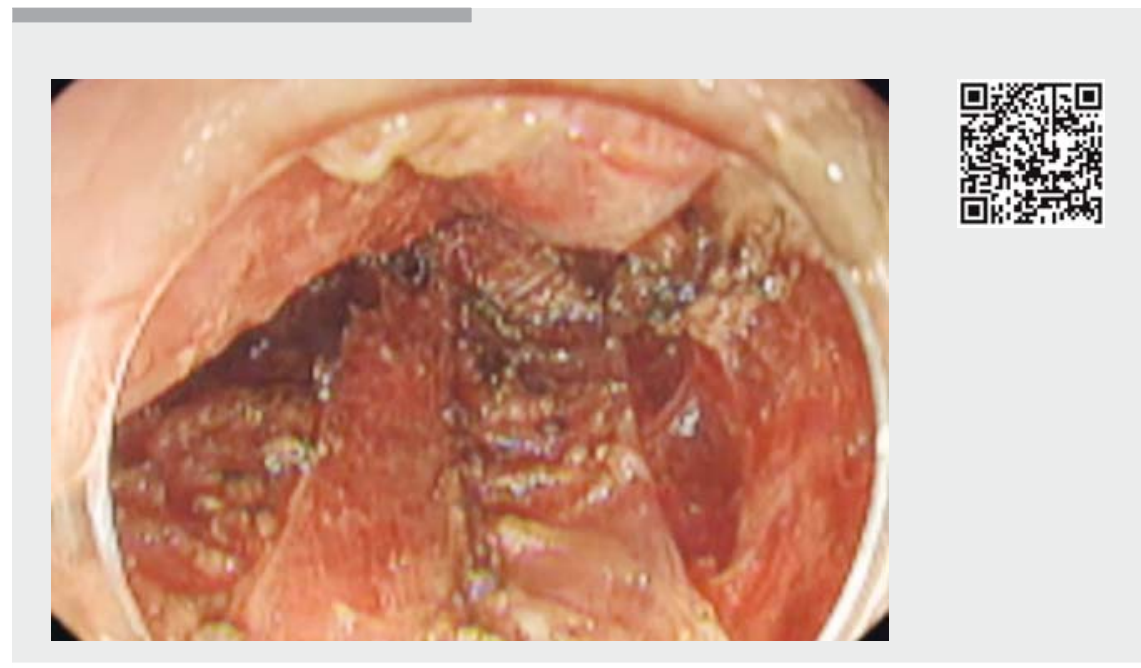

$\checkmark$ Video 1 Peroral endoscopic dual myotomy (dual POEM) technique for treating achalasia with severe esophageal dilatation in a 42-year-old man.

resolution of dysphagia, and barium series verified the success of the dual POEM procedure ( $\mathbf{F i g} \mathbf{1} \mathbf{b}$ ). No reflux complications were recorded.

Despite the excellent short-term outcome observed, dual POEM should be performed with great caution in selected patients. Further clinical studies with larger samples and long-term follow-up are needed to evaluate the effectiveness and safety of dual POEM for the treatment of achalasia with severe esophageal dilatation.

Endoscopy_UCTN_Code_TTT_1AO_2AH

\section{Competing interests}

None 

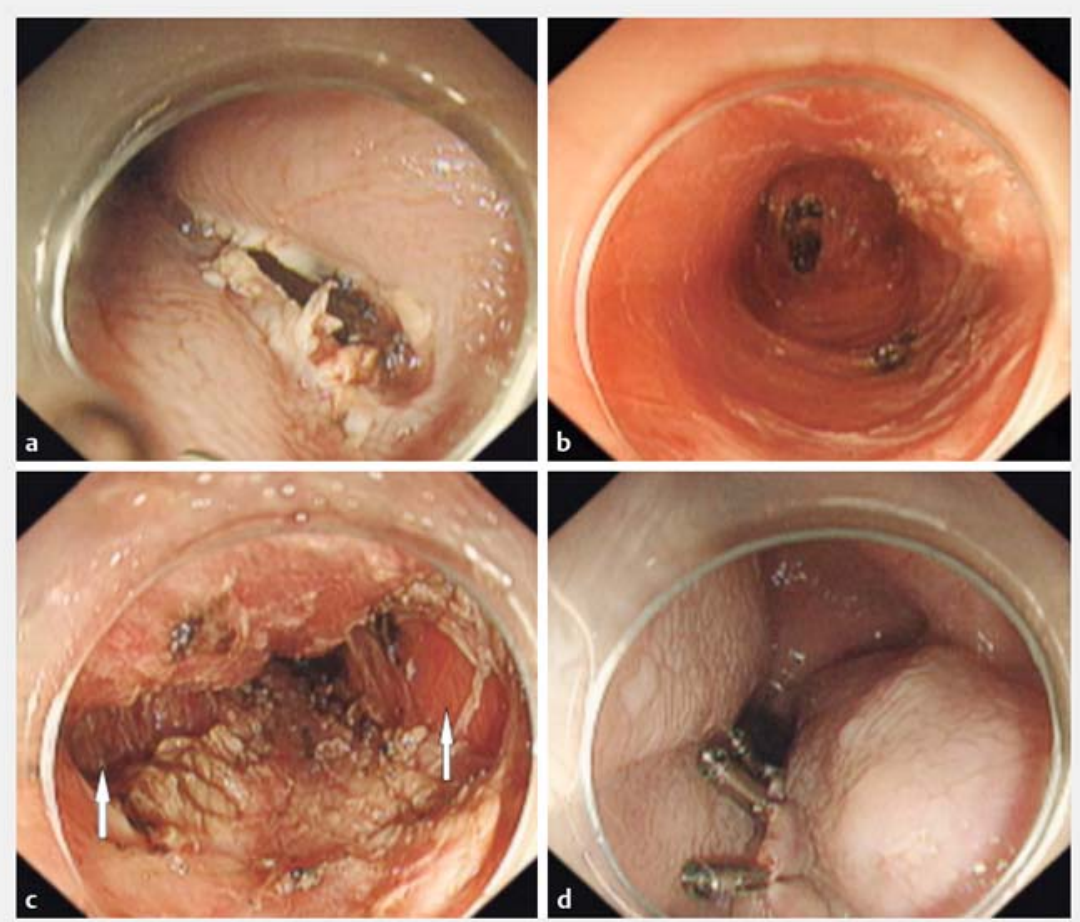

- Fig. 2 Peroral endoscopic dual myotomy (dual POEM) technique. a Mucosal entry was performed at the posterior wall of the esophagus using a hybrid knife. $\mathbf{b}$ A wide submucosal tunnel, occupying at least half of the esophageal lumen, was created. c Dual myotomies were performed successively at the 8 o'clock and 3 o'clock positions, respectively. $\mathbf{d}$ The mucosal entry was closed using clips.

The authors

Xiang-Lei Yuan “, Wei Liu“, Lian-Song Ye, Ping Yan, Yu Wang, Naveed Khan, Bing Hu Department of Gastroenterology, West China Hospital, Sichuan University, Sichuan, China

\footnotetext{
* These authors contributed equally to this work.
}

\section{Corresponding author}

\section{Bing Hu, MD}

Department of Gastroenterology, West China Hospital, Sichuan University, No. 37, Guo Xue Xiang, Chengdu, Sichuan, China 610041

Fax: $+86-028-85423387$

hubingnj@163.com

\section{Acknowledgment}

The authors want to thank the National Key R\&D Program of China (2017YFC0112305).

\section{References}

[1] Werner YB, Costamagna G, Swanstrom LL et al. Clinical response to peroral endoscopic myotomy in patients with idiopathic achalasia at a minimum follow-up of 2 years. Gut 2016; 65: 899-906

[2] Zaninotto G, Costantini M, Molena D et al. Treatment of esophageal achalasia with laparoscopic Heller myotomy and Dor partial anterior fundoplication: prospective evaluation of 100 consecutive patients. J Gastrointest Surg 2000; 4: 282-289

[3] Eckardt A], Eckardt VF. Treatment and surveillance strategies in achalasia: an update. Nat Rev Gastroenterol Hepatol 2011; 8: 311-319

[4] Kumbhari V, Tieu AH, Azola A et al. Double peroral endoscopic myotomy for achalasia. Gastrointest Endosc 2015; 82: 953

[5] Li QL, Yao LQ, Xu XY et al. Repeat peroral endoscopic myotomy: a salvage option for persistent/recurrent symptoms. Endoscopy 2016; 48: $134-140$

\section{Bibliography}

DOI https://doi.org/10.1055/a-0603-3099

Published online: 9.5.2018

Endoscopy 2018; 50: E179-E180

(C) Georg Thieme Verlag KG

Stuttgart · New York

ISSN 0013-726X

\section{ENDOSCOPY E-VIDEOS}

https://eref.thieme.de/e-videos

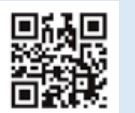

Endoscopy E-Videos is a free access online section, reporting on interesting cases and new techniques in gastroenterological endoscopy. All papers include a high quality video and all contributions are freely accessible online.

This section has its own submission website at

https://mc.manuscriptcentral.com/e-videos 